\title{
Epidural injections with or without steroids in managing chronic low back pain secondary to lumbar spinal stenosis: a meta-analysis of I 3 randomized controlled trials
}

\author{
This article was published in the following Dove Press journal: \\ Drug Design, Development and Therapy \\ 13 August 2015 \\ Number of times this article has been viewed
}

\author{
Hai Meng \\ Qi Fei \\ Bingqiang Wang \\ Yong Yang \\ Dong $\mathrm{Li}$ \\ Jinjun Li \\ $\mathrm{Nan} \mathrm{Su}$ \\ Department of Orthopedics, \\ Beijing Friendship Hospital, Capital \\ Medical University, Beijing, People's \\ Republic of China
}

Correspondence: Nan Su

Department of Orthopedics,

Beijing Friendship Hospital, Capital

Medical University, No 95, Yong'an Road,

Xicheng District, Beijing 100050, People's

Republic of China

Tel +86 I3 8I0I 48569

Email898988619@qq.com
Background: Epidural injections of anesthetic with or without steroids are widely used for treating lumbar spinal stenosis, a common cause of chronic low back pain, but there is a lack of rigorous data comparing the effectiveness of epidural injections of anesthetic with and without steroids. This meta-analysis presents a current, comprehensive picture of how epidural injections of anesthetic with steroids compare with those using local anesthetic alone.

Methods: PubMed, Embase, Web of Science, and Cochrane Library databases were searched from their inception through February 5, 2015. Weight mean difference, risk ratio, and 95\% confidence intervals were calculated. A random effects model or fixed effects model was used to pool the estimates, according to the heterogeneity between the included studies.

Results: We included 13 randomized controlled trials, involving 1,465 patients. Significant pain relief $(\geq 50 \%)$ was demonstrated in $53.7 \%$ of patients administered with epidural injections of anesthetic with steroids (group 1) and in $56.4 \%$ of those administered with local anesthetic alone (group 2). Patients showed a reduction in numeric rating scale pain score of 3.7 and 3.6 in the two groups, respectively. Significant functional improvement was achieved in $65.2 \%$ of patients in group 1 and $63.1 \%$ of patients in group 2, with Oswestry Disability Index reductions of 13.8 and 14.5 points, respectively. The overall number of injections per year was $3.2 \pm 1.3$ and $3.4 \pm 1.2$ with average total relief per year of $29.3 \pm 19.7$ and $33.8 \pm 19.3$ weeks, respectively. The opioid intakes decreased from baseline by 12.4 and $7.8 \mathrm{mg}$, respectively. Among the outcomes listed, only total relief time differed significantly between the two groups.

Conclusion: Both epidural injections with steroids or with local anesthetic alone provide significant pain relief and functional improvement in managing chronic low back pain secondary to lumbar spinal stenosis, and the inclusion of steroids confers no advantage compared to local anesthetic alone.

Keywords: chronic low back pain, spinal stenosis, epidural injections, steroids, local anesthetics

\section{Introduction}

Spinal stenosis is defined as a narrowing of spinal canal with encroachment on the neural structures by surrounding bone and soft issue. ${ }^{1}$ In the Framingham Study, prevalence of symptomatic lumbar spinal stenosis was estimated to be $27.2 \%$. $^{2}$ The three most common causes of low back and leg pain are spinal stenosis, disc herniation, and degenerative spondylolisthesis, for which surgery is usually performed. ${ }^{1,3-5}$ Moreover, in patients older than 65 years, lumbar spinal stenosis has been regarded as the most frequent indication for spinal surgery. ${ }^{4-6}$ Numerous modalities of treatment, 
including surgery with or without fusion, interventional techniques, and conservative approaches have been applied in managing lumbar central spinal stenosis.,7-9

Surgical interventions or epidural injections are commonly used for treatment of symptomatic spinal stenosis when conservative treatment fails..$^{1,3-5,10,11}$ In the Spine Patient Outcomes Research Trials (SPORT), Tosteson et $\mathrm{al}^{3}$ found that patients who received surgical intervention for spinal stenosis without degenerative spondylolisthesis achieved significant improvement in all primary outcomes compared to those undergoing nonsurgical treatment. Moreover, in a systematic review that compared conservative care with surgery, surgery was shown to provide beneficial effects in managing pain and quality of life, but not ambulation. ${ }^{12}$

However, for patients with mild to moderate spinal stenosis, who are not candidates for surgery, or for those who do not respond well to surgery, epidural injections may be the only interventional treatment. Consequently, apart from surgical intervention, epidural injections are the most commonly performed intervention in the management of chronic low back pain secondary to central spinal stenosis. ${ }^{13,14}$ Manchikanti et al conducted a trial that compared the effect of epidural injections with or without steroids in the treatment of spinal stenosis. ${ }^{15}$ The authors found that $46 \%$ of the patients who were treated with local anesthetic and steroids achieved significant pain relief and an improvement in functional status of more than $50 \%$, whereas the proportion of patients who improved after receiving only local anesthetic was $48 \% .{ }^{15}$ In another trial, pain relief and improved functional status were observed in $73 \%$ of the patients who received both steroids and local anesthetic, and in $72 \%$ of those who received local anesthetic alone. ${ }^{16}$

No meta-analysis has yet been conducted to compare the effectiveness of epidural injections of local anesthetic with or without steroids in the treatment of patients with spinal stenosis, leaving the relative effectiveness of these treatments open to question. To address this need, we performed a metaanalysis based on randomized controlled trials (RCTs).

\section{Methods and materials}

\section{Search strategy and study inclusion}

We followed the preferred reported items for systematic and meta-analysis guideline (PRISMA) in this study. ${ }^{17}$ A comprehensive literature search was conducted to identify all the published RCTs that compared epidural injection with or without steroids in the management of chronic low back pain in spinal stenosis. PubMed, Embase, Web of Science, and Cochrane Library databases were searched from their inception through February 5, 2015. The following search terms were used: ("spinal stenosis" [MeSH Terms]) or ("spinal" [All Fields] and "stenosis" [All Fields]) or ("spinal stenosis" [All Fields]) and ("injections, epidural" [MeSH Terms]) or ("injections" [All Fields] and "epidural" [All Fields]) or ("epidural injections" [All Fields]) or ("epidural" [All Fields] and "injection" [All Fields]) or ("epidural injection" [All Fields]) and ("anesthetics, local" [Pharmacological Action] or "anesthetics, local" [MeSH Terms]) or ("anesthetics" [All Fields] and "local"[All Fields]) or ("local anesthetics" [All Fields]) or ("local" [All Fields] and "anesthetic" [All Fields]) or ("local anesthetic" [All Fields]) or ("anesthesia, local" [MeSH Terms]) or ("anesthesia" [All Fields] and "local" [All Fields]) or ("local anesthesia" [All Fields]) or ("local" [All Fields] and "anesthetic" [All Fields]) and ("steroids" [MeSH Terms] or "steroids" [All Fields] or "steroid" [All Fields]). We did not impose any language limitation in the search strategy. Reference lists of the included studies were also manually screened until no more potential studies could be found.

Studies that met the following selection criteria were included in this meta-analysis: 1) study design: RCT; 2) study subjects: patients diagnosed with spinal stenosis with radicular pain who had a history of chronic function-limiting low back pain and lower extremity pain; 3) study intervention: patients in the study arm received epidural injections of local anesthetic with steroids, whereas patients in the control arm received local anesthetic alone; 4) outcomes: pain relief, numeric rating scale (NRS) of the pain rating scores, functional improvement, Oswestry Disability Index (ODI) of functional ability, opioid intake, average number of injections per year, total relief per year, and weight changes.

\section{Data extraction and quality assessment}

Two independent investigators (Nan Su and Hai Meng) extracted the following information from each included study: first author, year of publication, number of patients (intervention/control arms), baseline characteristics, number of patients with significant ( $\geq 50 \%$ ) pain relief or improvement in functional status in each group, average number of injections per year in each group, total relief time per year in each group, opioid intake, and weight changes.

The methodological quality of all the included studies was assessed using the Jadad scale. ${ }^{18}$ The scale consists of three items in the report of an RCT. The quality scale ranges from 0 to 5 points, with a higher score indicating a better quality study. Articles with a score of more than 2 are deemed to be of high quality. ${ }^{19}$ 
Table I The literature search strategy for each database

\begin{tabular}{ll}
\hline Database & Search terms \\
\hline PubMed & "Spinal stenosis" and "epidural injections of anesthetic" and "steroids" \\
Embase & "Spinal stenosis" and "epidural injections of anesthetic" and "steroids" (human and \\
& exclude Medline journal and Embase and randomized controlled trials and article) \\
Web of Science & Spinal stenosis*epidural injections of anesthetic*steroids \\
Cochrane Library database & "Spinal stenosis" and "epidural injections of anesthetic" and "steroids" \\
\hline
\end{tabular}

\section{Statistical analysis}

This meta-analysis was conducted based on the data from 13 randomized trials. Pain relief and functional status improvement were treated as dichotomous variables and were expressed as a risk ratio (RR) with a $95 \%$ confidence interval (CI). The NRS, ODI, total relief per year, opioid intake, average number of injections per year, and weight change were treated as continuous variables and were expressed as a weight mean difference (WMD) with $95 \%$ CI. Before the data were pooled, a Cochrane Q chi-square test and $I^{2}$ statistic were used to test the heterogeneity between studies, in which a $P$-value of less than 0.1 or $I^{2}$ value of more than $50 \%$ were considered indicators of significant heterogeneity. ${ }^{20} \mathrm{~A}$ fixed effects model was used to pool the estimates when substantial heterogeneity existed; ${ }^{21}$ otherwise a random effects model was preferred to summarize the data. ${ }^{22}$ The presence of publication bias was assessed by using the $\mathrm{Begg}^{22}$ and Egger test. ${ }^{23} \mathrm{~A} P$-value $<0.05$ was judged as statistically significant, except where otherwise specified. All analyses were performed using STATA version 12.0 (Stata Corporation, College Station, TX, USA).

\section{Results}

\section{Identification of eligible studies}

The initial search yielded 586 studies from the three databases (Table 1), of which 376 were excluded because of duplicate records. After the title and abstract review, 195 were excluded, leaving 15 for the full-text review. Of those remaining, two studies were excluded because one was a study protocol, ${ }^{24}$ and the other ${ }^{25}$ contained data redundant with that in a later, completed version of the study. Ultimately, 13 RCTs with a total of 1,465 patients that met the inclusion criteria were included in this meta-analysis. ${ }^{8,9,26-36}$ A flowchart of the literature search strategy is shown in Figure 1.

\section{Study characteristics and quality assessment}

The main characteristics of the 13 RCTs included in our analysis are summarized in Table 2. All these trials were strictly selected according to the selection criteria. Trials were published between 1998 and 2004, all in peer-reviewed journals. Sample sizes in the included studies ranged from 19 to 400 . Of the 13 studies, five $e^{8,27-30}$ used the caudal route to administer anesthetic or steroids, three $e^{9,35,36}$ used an interlaminar route, two used a transforaminal route, and the remaining three ${ }^{31,33,34} \mathrm{did}$ not report the administration route. In majority of the studies, the NRS was used to evaluate pain rating scores, and the ODI was used to measure functional ability, with lower scores indicating less severe symptoms. A $50 \%$ or greater reduction in NRS or ODI scores was considered as significant pain relief and improvement. The median Jadad score of the included studies was 4 (range from 4 to 5).

\section{Pain relief}

Pain relief data were reported in nine studies. . $^{8,26-30,33,36}$ Pooling these RCTs, significant pain relief was demonstrated in $51.5 \%$ of patients in both groups at 3 months, $56.6 \%$ in

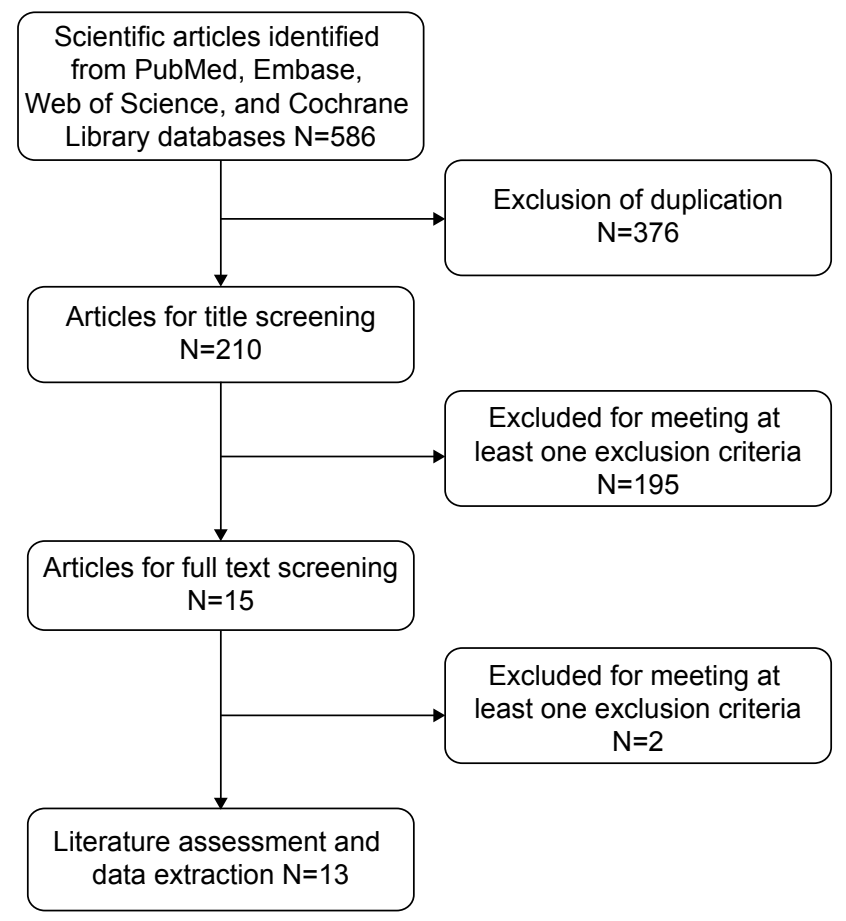

Figure I Eligibility of studies for inclusion in systematic review. 


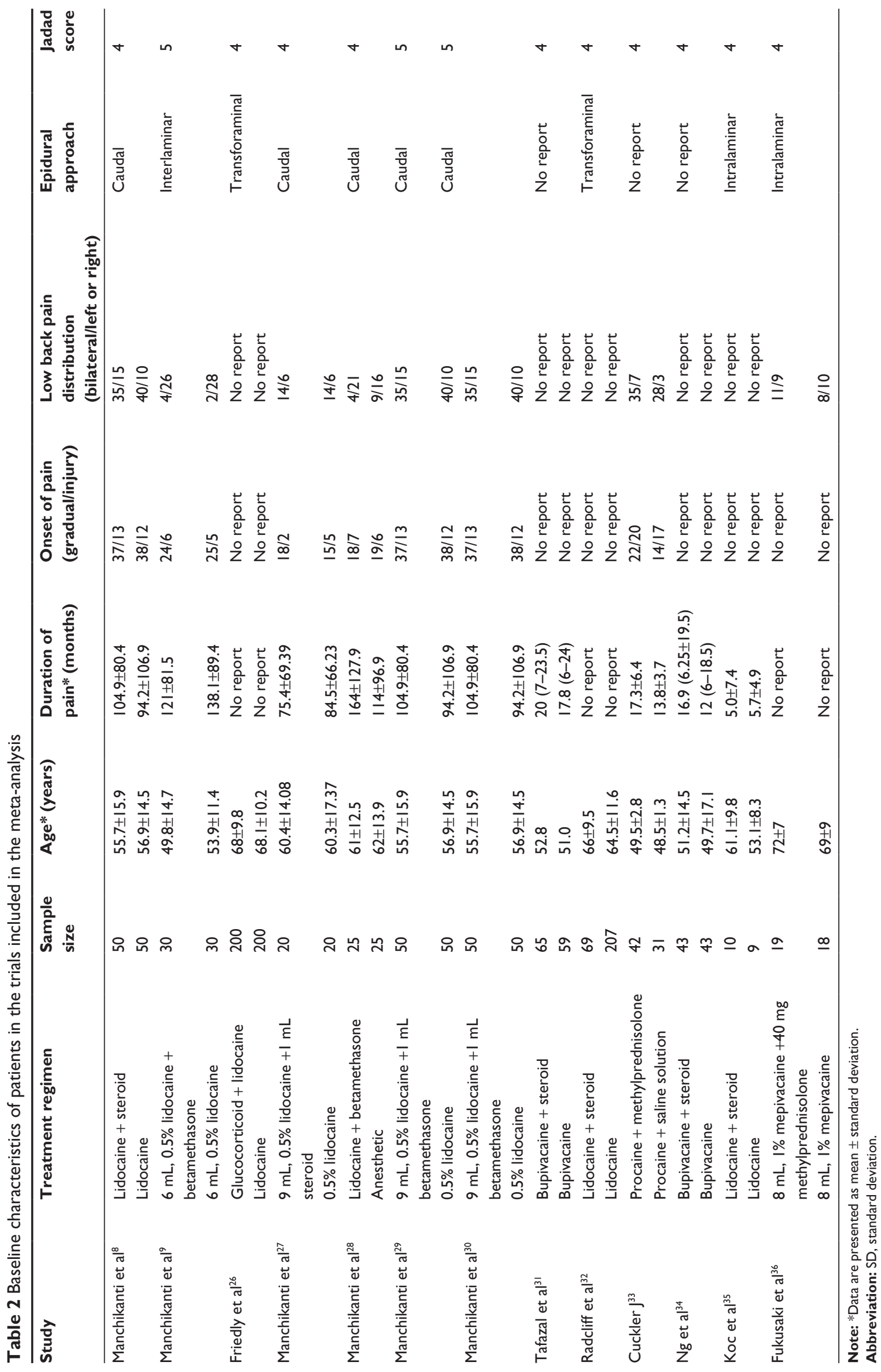


both groups at 6 months, and $53.7 \%$ in group 1 and $56.4 \%$ in group 2 at 12 months. Meta-analysis of nine RCTs using a fixed effects model showed that there were no significant differences between the two groups in terms of pain relief at 3 months (RR $=1.0,95 \%$ CI: 0.9, 1.2; $P=0.975), 6$ months (RR $=1.0,95 \%$ CI: $0.9,1.1 ; P=1.000)$, or 12 months ( $\mathrm{RR}=1.0,95 \% \mathrm{CI}: 0.9,1.2 ; P=1.000$ ) (Figure 2).

Data of NRS pain scores were available from ten studies. ${ }^{8,9,26-31,33,35}$ Pooled estimates indicated that in group 1, patients at 3,6, and 12 months had a 5.3 score reduction (WMD $=-5.3,95 \%$ CI: $-6.7,-3.8 ; P=0.000$ ), 4.0 score reduction (WMD $=-4.0,95 \% \mathrm{CI}:-5.0,-3.0 ; P=0.000$ ), and 3.7 score reduction (WMD $=-3.7,95 \% \mathrm{CI}:-4.0,-3.4$; $P=0.000$ ), respectively; whereas, patients in group 2 had a 4.9 score reduction (WMD $=-4.9,95 \% \mathrm{CI}$ : $-6.4,-3.3$; $P=0.000$ ), 4.5 score reduction (WMD $=-4.5,95 \% \mathrm{CI}:-5.8,-3.1$; $P=0.000$ ), and 3.6 score reduction (WMD $=-3.6,95 \%$ CI: $-4.4,-2.8 ; P=0.000)$, respectively. However, there were no significant differences in terms of NRS pain scores between the two groups at 3 months (WMD $=-0.2,95 \%$
CI: $-0.8,0.5 ; P=0.586$ ), 6 months (WMD $=-0.2,95 \%$ CI: $-1.0,0.6 ; P=0.607)$, or 12 months (WMD $=-0.3,95 \%$ CI: $-1.3,0.6 ; P=0.490$ ) (Figure 3).

\section{Functional assessment}

Seven studies reported data on functional assessment. ${ }^{8,9,26-30}$ The pooled estimates showed that in group 1 and group 2, $42.7 \%$ and $40.3 \%$ of patients at 3 months, $58.5 \%$ and $60.0 \%$ of patients at 6 months, and $65.2 \%$ and $63.1 \%$ of patients at 12 months, respectively, achieved a significant functional improvement. However, no significant differences of functional improvement were found between the two groups at 3 months (RR $=1.0,95 \%$ CI: 0.9, 1.2; $P=0.669), 6$ months (RR $=1.0,95 \%$ CI: $0.9,1.2 ; P=1.000)$, or 12 months $(\mathrm{RR}=1.0$, 95\% CI: 0.8, 1.1; $P=0.761$ ) (Figure 4).

Data on ODI were available from ten studies..$^{8,9,26-32,34}$ Pooled estimates suggest that in group 1, patients at 3,6, and 12 months had a 13.2 point reduction $(\mathrm{WMD}=-13.2,95 \% \mathrm{CI}:-18.6,-7.7$; $P=0.000$ ), 12.1 point reduction (WMD $=-12.1,95 \%$ CI: $-19.5,-4.8 ; P=0.001)$, and 13.8 point reduction

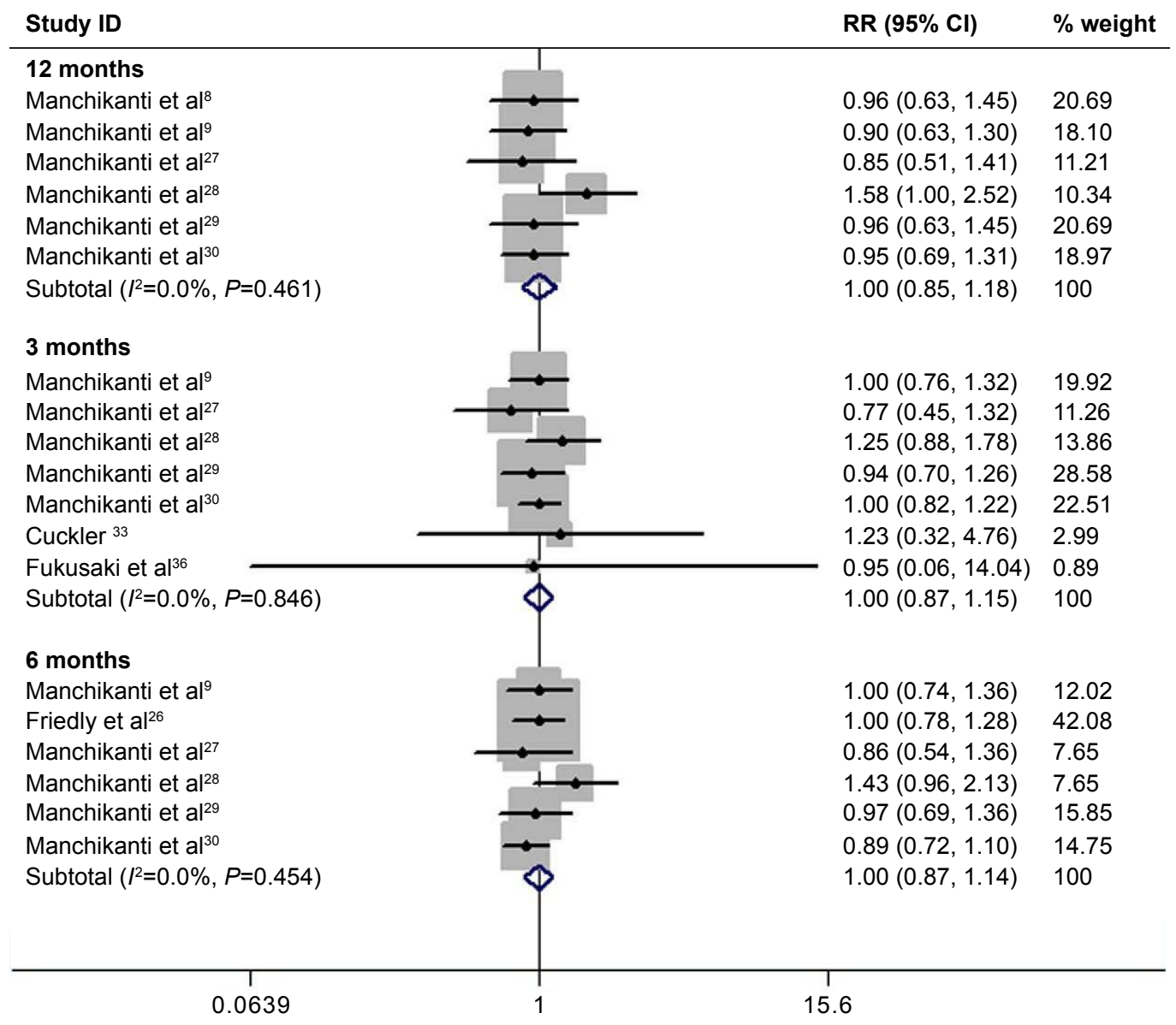

Figure 2 Comparison of pain relief improvements between epidural injections with or without steroids for patients with lumbar spinal stenosis. Abbreviations: $\mathrm{RR}$, risk ratio; $\mathrm{Cl}$, confidence interval. 


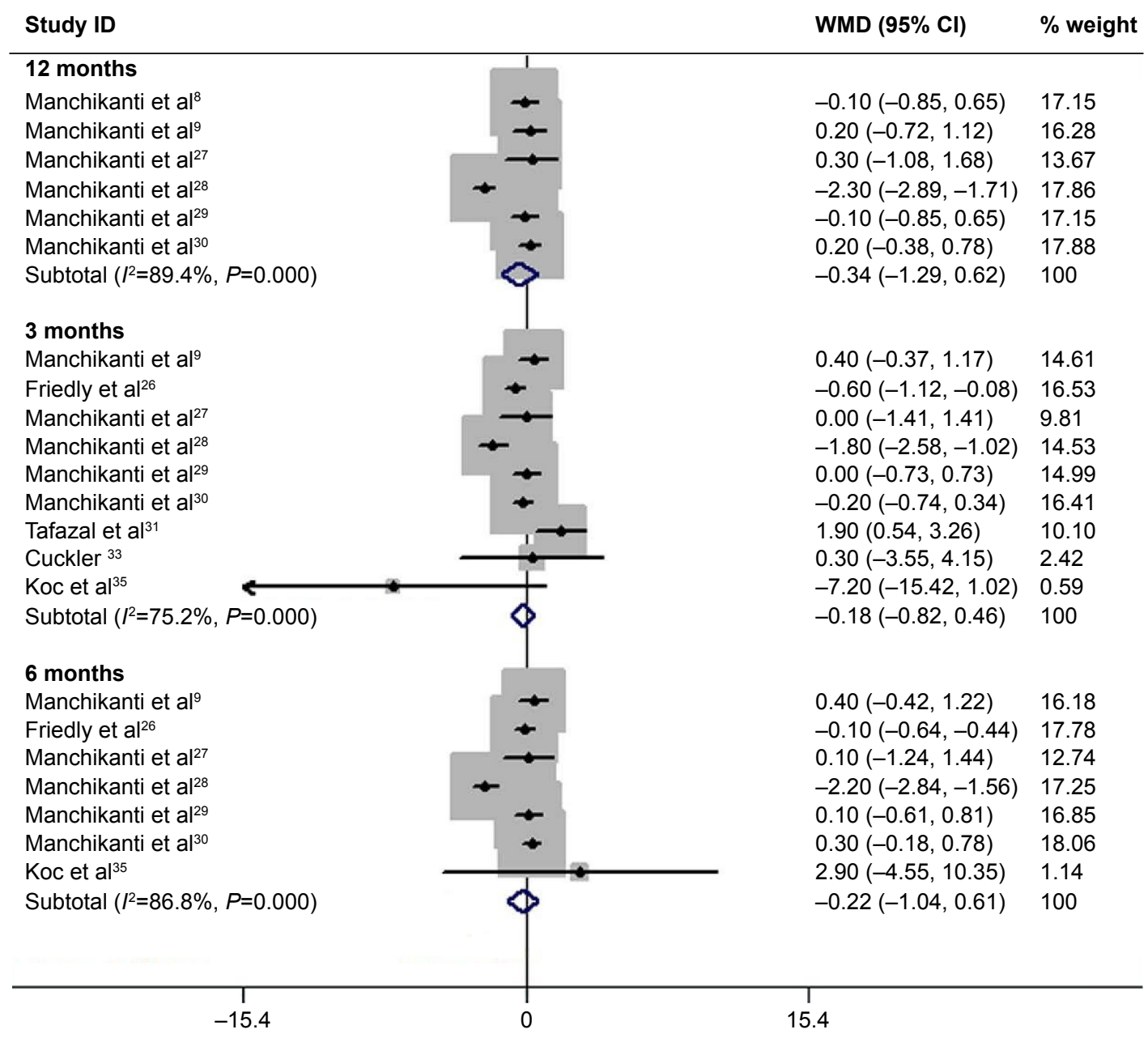

Figure 3 Comparison of NRS pain scores between epidural injections with or without steroids for patients with lumbar spinal stenosis. Note: Weights are from random effects analysis.

Abbreviations: NRS, numeric rating scale; WMD, weight mean difference; $\mathrm{Cl}$, confidence interval.

(WMD $=-13.8,95 \% \mathrm{CI}:-16.2,-11.5 ; P=0.000)$, respectively; whereas, patients in group 2 had a 12.9 point reduction (WMD =-12.9, 95\% CI: $-18.6,-7.3 ; P=0.000), 12.8$ point reduction $(\mathrm{WMD}=-12.8,95 \% \mathrm{CI}:-20.2,-5.3 ; P=0.001)$, and 14.5 point reduction $(\mathrm{WMD}=-14.5,95 \% \mathrm{CI}:-16.1,-12.8$; $P=0.000$ ), respectively. However, there were no significant differences in terms of ODI between the two groups at 3 months (WMD $=-0.1,95 \% \mathrm{CI}:-0.2,0.0 ; P=0.096$ ), 6 months $(\mathrm{WMD}=0.1,95 \% \mathrm{CI}: 0.0,0.2 ; P=0.123)$, or 12 months (WMD $=-0.3,95 \%$ CI: $-1.0,0.4 ; P=0.439)$ (Figure 5).

\section{Opioid intake}

Six studies provided data on opioid intake. , $9,27-30^{\text {Signifi- }}$ cant reductions from baseline were observed in group 1, by $11.8 \mathrm{mg}(\mathrm{WMD}=-11.8,95 \% \mathrm{CI}:-18.0,-5.6 ; P=0.000), 12.3$ $\operatorname{mg}(\mathrm{WMD}=-12.3,95 \% \mathrm{CI}:-18.6,-6.0 ; P=0.001)$, and 12.4 $\operatorname{mg}(\mathrm{WMD}=-12.4,95 \% \mathrm{CI}:-18.7,-6.0 ; P=0.000)$ at 3,6 , and 12 months, respectively; whereas in group 2, reductions were $8.4 \mathrm{mg}(\mathrm{WMD}=-8.4,95 \% \mathrm{CI}:-14.0,-2.9 ; P=0.000)$, $8.2 \mathrm{mg}(\mathrm{WMD}=-8.2,95 \% \mathrm{CI}:-13.8,-2.6 ; P=0.001)$, and $7.8 \mathrm{mg}$ (WMD $=-7.8,95 \% \mathrm{CI}:-13.4,-2.2 ; P=0.000)$, respectively. No significant differences between the two groups were found at 3 months (WMD $=-0.0,95 \% \mathrm{CI}:-5.0$, 4.9; $P=0.096), 6$ months (WMD $=0.7,95 \% \mathrm{CI}:-3.7,5.0$; $P=0.123$ ), or 12 months (WMD $=0.6,95 \% \mathrm{CI}:-3.6,4.9$; $P=0.439$ ) (Figure 6).

\section{Therapeutic procedural characteristics}

Six studies reported data on the frequency of injections..$^{8,9,27-30}$ Pooled estimates using a fixed effects model showed that there was no significant difference in the average number of injections per year between the two groups $(\mathrm{WMD}=-0.2$, 95\% CI: $-0.4,0.0 ; P=0.099)$.

Six studies reported data on total relief time. ${ }^{8,9,27-30}$ Pooled analysis using a fixed effects model indicated that patients in group 1 had 4.5 weeks of average total relief per year less 


\begin{tabular}{|c|c|c|}
\hline Study ID & $\operatorname{RR}(95 \% \mathrm{Cl})$ & $\%$ weight \\
\hline \multicolumn{3}{|l|}{12 months } \\
\hline Manchikanti et al ${ }^{8}$ & $1.00(0.68,1.48)$ & 20.33 \\
\hline Manchikanti et al ${ }^{9}$ & $0.86(0.59,1.25)$ & 17.07 \\
\hline Manchikanti et al ${ }^{27}$ & $0.69(0.44,1.08)$ & 13.01 \\
\hline Manchikanti et al ${ }^{28}$ & $1.54(1.01,2.35)$ & 10.57 \\
\hline Manchikanti et al ${ }^{29}$ & $1.00(0.68,1.48)$ & 20.33 \\
\hline Manchikanti et al ${ }^{30}$ & $0.91(0.67,1.24)$ & 18.70 \\
\hline Subtotal $\left(I^{2}=32.3 \%, P=0.194\right)$ & $0.98(0.83,1.14)$ & 100 \\
\hline \multicolumn{3}{|l|}{3 months } \\
\hline Manchikanti et al ${ }^{9}$ & $0.79(0.57,1.10)$ & 16.78 \\
\hline Friedly et $\mathrm{al}^{26}$ & $1.20(0.83,1.74)$ & 27.97 \\
\hline Manchikanti et al ${ }^{27}$ & $0.77(0.45,1.32)$ & 9.09 \\
\hline Manchikanti et $\mathrm{al}^{28}$ & $1.43(0.96,2.13)$ & 9.79 \\
\hline Manchikanti et al ${ }^{29}$ & $0.86(0.60,1.24)$ & 20.28 \\
\hline Manchikanti et $\mathrm{al}^{30}$ & $1.13(0.89,1.44)$ & 16.08 \\
\hline Subtotal $\left(I^{2}=40.1 \%, P=0.138\right)$ & $1.03(0.88,1.21)$ & 100 \\
\hline \multicolumn{3}{|l|}{6 months } \\
\hline Manchikanti et al ${ }^{9}$ & $1.00(0.70,1.43)$ & 19.80 \\
\hline Manchikanti et $\mathrm{al}^{27}$ & $0.80(0.52,1.24)$ & 14.85 \\
\hline Manchikanti et al ${ }^{28}$ & $1.46(0.94,2.26)$ & 12.87 \\
\hline Manchikanti et al ${ }^{29}$ & $0.93(0.63,1.35)$ & 26.73 \\
\hline Manchikanti et al ${ }^{30}$ & $0.96(0.78,1.19)$ & 25.74 \\
\hline Subtotal $\left(I^{2}=4.6 \%, P=0.381\right)$ & $1.00(0.85,1.17)$ & 100 \\
\hline 0.425 & & \\
\hline
\end{tabular}

Figure 4 Comparison of functional improvements between epidural injections with or without steroids for patients with lumbar spinal stenosis. Abbreviations: $\mathrm{RR}$, risk ratio; $\mathrm{Cl}$, confidence interval.

than those in group $2(\mathrm{WMD}=-4.5,95 \% \mathrm{CI}:-8.2,-0.7$; $P=0.019)$.

Five studies reported data on changes in weight. ${ }^{8,9,27,29,30}$ Pooled estimates using a fixed effects model showed that there was no significant difference in weight change between the two groups (WMD $=1.7,95 \% \mathrm{CI}$ : $-0.2,3.5 ; P=0.077$ ).

\section{Publication bias}

Egger's and Begg's tests were used to assess publication bias among the included studies. We found no potential publication bias according to either Egger's $(t=0.6, P=0.566)$ or Begg's tests $(Z=0.4, P=0.700)$.

\section{Discussion}

To the best of our knowledge, this is the first meta-analysis to assess the effectiveness of epidural injections with or without steroids in the treatment of chronic pain related to spinal stenosis. Our analysis of 13 RCTs showed that significant pain relief ( $\geq 50 \%$ ) was demonstrated in $53.7 \%$ of patients in group 1 and $56.4 \%$ of patients in group 2 .
Patients showed a reduction in NRS pain score of 3.7 and 3.6 in the two groups, respectively. Significant functional improvement was achieved in $65.2 \%$ and $63.1 \%$ of patients in groups 1 and 2, with an ODI reduction of 13.8 points and 14.5 points, respectively. The overall number of injections per year was $3.2 \pm 1.3$ and $3.4 \pm 1.2$ with average total relief per year of $29.3 \pm 19.7$ and $33.8 \pm 19.3$ weeks in groups 1 and 2, respectively, and the opioid intakes decreased from baseline by 12.4 and $7.8 \mathrm{mg}$, respectively. However, there were no significant differences between the two groups in terms of the outcomes mentioned earlier except in the total relief time.

It is challenging to treat the disabling pain associated with spinal stenosis, with or without surgery. A previous report, ${ }^{3}$ showed surgery to be more effective than conservative management. However, no studies with the criteria of contemporary interventional pain management have been conducted to assess the conservative management approach used in the past. Consequently, the most effective management strategy for spinal stenosis has not been still 


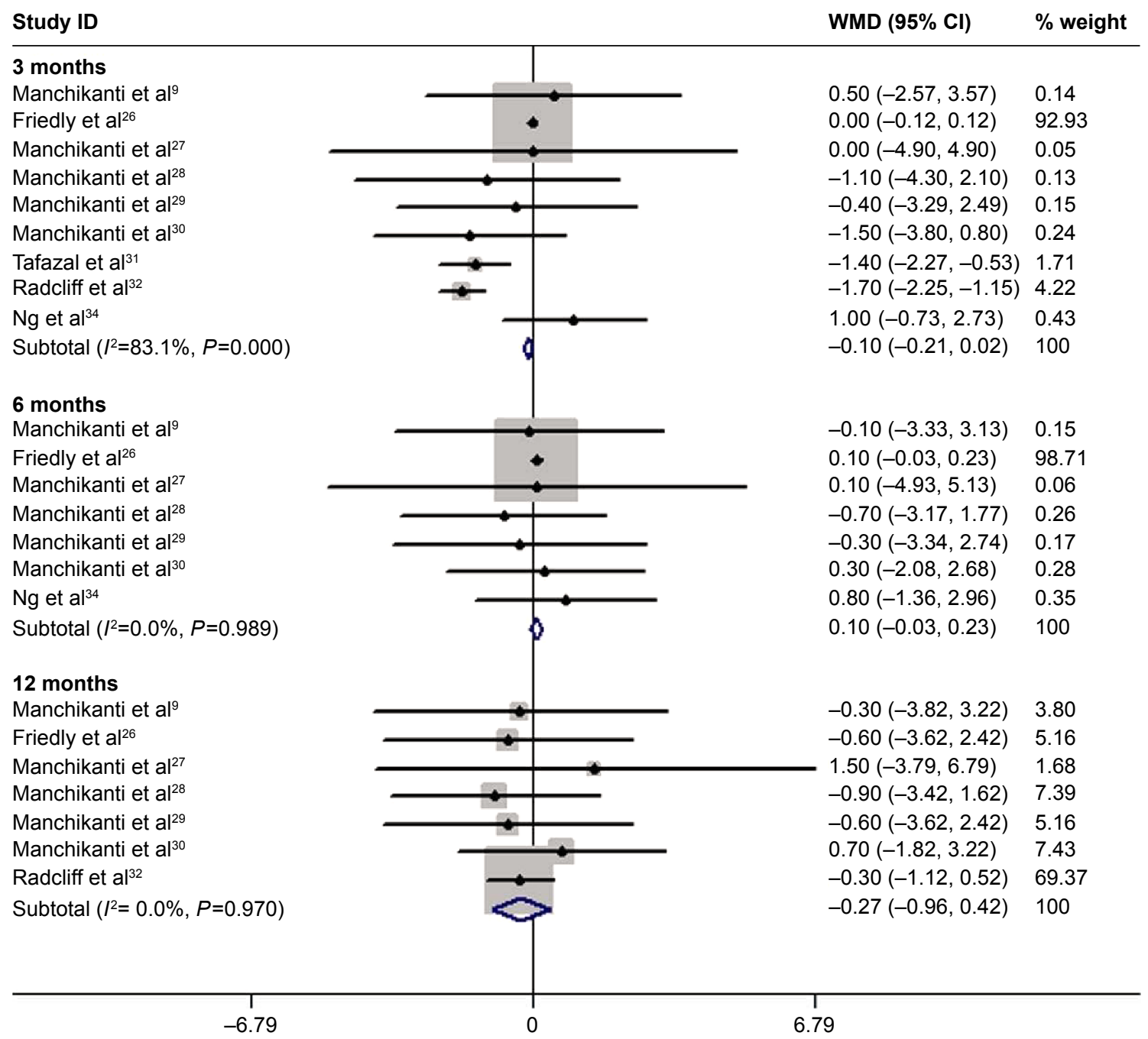

Figure 5 Comparison of ODI between epidural injections with or without steroids for patients with lumbar spinal stenosis. Abbreviations: ODI, Oswestry Disability Index; WMD, weight mean difference; $\mathrm{Cl}$, confidence interval.

determined, even though the condition was first reported in 1954, when it was characterized by the narrowing of spinal canal, neurogenic spinal claudication, and radicular pain. ${ }^{37}$ Reports indicate that only a subgroup of patients has a good response to surgical intervention for spinal stenosis, whereas other subgroups of patients respond well to epidural injections. ${ }^{7,8}$ However, until now no studies could explicitly delineate the characteristics of these subgroups. Future studies should focus on these issues.

The mechanisms by which epidural injections with steroids produce beneficial effects in pain relief and functional status improvement are not entirely known. It is hypothesized that the anti-inflammatory properties of steroids are responsible for the neural blockade. ${ }^{38-41}$ Emerging evidence demonstrates that local anesthetics may be as effective as steroids in the management of low back pain, without disc herniation originating at the facet joint, and in some other types of nerve block. ${ }^{42-45}$ This was also verified in a recently published systematic review and meta-analysis. ${ }^{46}$ In that study, the authors summarized ten RCTs to compare the effectiveness of epidural steroid injection to that of local anesthetic in patients with lumbar spinal stenosis. The pooled results showed minimal or no significant difference between the epidural steroid injection group and the local anesthetic injection group for short-term benefit, specifically, changes in leg pain VAS score (WMD $=-7.00,95 \%$ CI: $-12.73,-1.27 ; P=0.02)$, changes in back pain VAS score (WMD $=0.60,95 \% \mathrm{CI}: 0.07,1.13 ; P=0.03$ ), and Swiss Spinal Stenosis Questionnaire (SSSQ) subscales for symptoms (WMD $=-0.2,95 \% \mathrm{CI}:-0.34,-0.06 ; P=0.05){ }^{46}$ Therefore, the authors concluded that compared with local anesthetic, epidural steroid injection therapy provided no statistically significant improvement in pain symptoms or walking ability in lumbar spinal stenosis patients. ${ }^{46}$ On the 


\begin{tabular}{|c|c|c|}
\hline Study ID & WMD (95\% Cl) & $\%$ weight \\
\hline \multicolumn{3}{|l|}{6 months } \\
\hline Manchikanti et $\mathrm{al}^{8}$ & $-0.70(-16.02,14.62)$ & 7.93 \\
\hline Manchikanti et al ${ }^{9}$ & $4.87(-1.59,11.33)$ & 44.51 \\
\hline Manchikanti et $\mathrm{al}^{27}$ & $-14.60(-39.39,10.19)$ & 3.03 \\
\hline Manchikanti et al ${ }^{28}$ & $-3.00(-10.36,4.36)$ & 34.34 \\
\hline Manchikanti et $\mathrm{al}^{29}$ & $-0.70(-16.02,14.62)$ & 7.93 \\
\hline Manchikanti et $\mathrm{al}^{30}$ & $3.57(-25.16,32.30)$ & 2.25 \\
\hline Subtotal $\left(I^{2}=0.0 \%, P=0.530\right)$ & $0.67(-3.65,4.98)$ & 100 \\
\hline \multicolumn{3}{|l|}{12 months } \\
\hline Manchikanti et $\mathrm{al}^{8}$ & $-2.60(-17.90,12.70)$ & 7.74 \\
\hline Manchikanti et $\mathrm{al}^{9}$ & $5.37(-0.95,11.69)$ & 45.37 \\
\hline Manchikanti et $\mathrm{al}^{27}$ & $-14.60(-39.39,10.19)$ & 2.95 \\
\hline Manchikanti et $\mathrm{al}^{28}$ & $-3.00(-10.30,4.30)$ & 33.99 \\
\hline Manchikanti et al ${ }^{29}$ & $-2.60(-17.90,12.70)$ & 7.74 \\
\hline Manchikanti et $\mathrm{al}^{30}$ & $2.57(-26.02,31.16)$ & 2.22 \\
\hline Subtotal $\left(I^{2}=0.0 \%, P=0.426\right)$ & $0.64(-3.62,4.90)$ & 100 \\
\hline \multicolumn{3}{|l|}{3 months } \\
\hline Manchikanti et $\mathrm{al}^{8}$ & $-0.20(-12.69,12.29)$ & 15.51 \\
\hline Manchikanti et al ${ }^{9}$ & $11.54(-0.64,23.72)$ & 16.31 \\
\hline Manchikanti et $\mathrm{al}^{27}$ & $-14.40(-39.08,10.28)$ & 3.97 \\
\hline Manchikanti et $\mathrm{al}^{28}$ & $-3.00(-10.27,4.27)$ & 45.76 \\
\hline Manchikanti et $\mathrm{al}^{29}$ & $-0.20(-12.69,12.29)$ & 15.51 \\
\hline Manchikanti et $\mathrm{al}^{30}$ & $3.40(-25.28,32.08)$ & 2.94 \\
\hline Subtotal $\left(I^{2}=8.5 \%, P=0.362\right)$ & $-0.03(-4.94,4.89)$ & 100 \\
\hline $\begin{array}{c}1 \\
-39.4\end{array}$ & & \\
\hline
\end{tabular}

Figure 6 Comparison of opioid intake between epidural injections with or without steroids for patients with lumbar spinal stenosis. Abbreviations: WMD, weight mean difference; $\mathrm{Cl}$, confidence interval.

basis of their report, patients with spinal stenosis would be expected to improve symptomatically with epidural injection of local anesthetic or with steroids.

Additionally, emphasis should be placed on the targeted delivery of the injectate to the site of pathology. It is reported that the use of blind approach to epidural procedures is the main reason for failed responses. According to the previous publications, inappropriate placement of drug because of inaccurate injection had occurred in $20 \%-38 \%$ of the patients. ${ }^{47-49}$ The use of fluoroscopy to guide epidural injections is therefore essential to ensure accurate and consistent drug placement at the target site.

There are some limitations in this meta-analysis, which should be taken into account when interpreting our results. First, we acknowledge that the studies we included lack homogeneity in their approaches to epidural injection, as well as in dosing, injection frequency, and length of follow-up. These differences potentially influence the treatment effects reported. Second, our meta-analysis included several studies with relatively small numbers of patients $(n<50$ in three studies), and in some the relevant data was incomplete. Third, injection routes are important factors that influence the treatment effect of epidural injections with steroids, and there are debates about the effects of three epidural injection routes (transforaminal epidural injection, caudal epidural injection, and interlaminar approach). Because of limited reporting across the trials, we did not compare the effects or long-term effectiveness of epidural injection with steroids between the different injection routes.

\section{Conclusion}

This study shows that epidural injections, with or without steroids, are effective in managing chronic low back pain secondary to spinal stenosis. However, the inclusion of steroids does not provide any additional benefit compared with injection of local anesthetic alone. Therefore, on the basis of the current findings, there is a lack of evidence to support that the addition of steroids to epidural injections provides 
benefit in patients with spinal stenosis. Further, large-scale, well-conducted RCTs are required to clearly determine the effectiveness of epidural injections with steroids in the treatment of spinal stenosis.

\section{Disclosure}

The authors report no conflicts of interest in this work.

\section{References}

1. Haig AJ, Tomkins CC. Diagnosis and management of lumbar spinal stenosis. JAMA. 2010;303(1):71-72.

2. Kalichman L, Cole R, Kim DH, et al. Spinal stenosis prevalence and association with symptoms: the Framingham Study. Spine J. 2009;9(7): $545-550$.

3. Tosteson AN, Tosteson TD, Lurie JD, et al. Comparative effectiveness evidence from the spine patient outcomes research trial: surgical versus nonoperative care for spinal stenosis, degenerative spondylolisthesis, and intervertebral disc herniation. Spine. 2011;36(24):2061-2068.

4. Deyo RA, Mirza SK, Martin BI, Kreuter W, Goodman DC, Jarvik JG. Trends, major medical complications, and charges associated with surgery for lumbar spinal stenosis in older adults. JAMA. 2010;303(13): $1259-1265$.

5. Chen E, Tong KB, Laouri M. Surgical treatment patterns among Medicare beneficiaries newly diagnosed with lumbar spinal stenosis. Spine J. 2010;10(7):588-594.

6. Cummins J, Lurie JD, Tosteson TD, et al. Descriptive epidemiology and prior healthcare utilization of patients in the Spine Patient Outcomes Research Trial's (SPORT) three observational cohorts: disc herniation, spinal stenosis, and degenerative spondylolisthesis. Spine. 2006;31(7): 806-814.

7. Tosteson AN, Lurie JD, Tosteson TD, et al. Surgical treatment of spinal stenosis with and without degenerative spondylolisthesis: costeffectiveness after 2 years. Ann Intern Med. 2008;149(12):845-853.

8. Manchikanti L, Cash KA, McManus CD, Pampati V, Fellows B. Fluoroscopic caudal epidural injections with or without steroids in managing pain of lumbar spinal stenosis: one-year results of randomized, double-blind, active-controlled trial. J Spinal Disord Tech. 2012;25(4): 226-234.

9. Manchikanti L, Cash KA, McManus CD, Damron KS, Pampati V, Falco FJ. Lumbar interlaminar epidural injections in central spinal stenosis: preliminary results of a randomized, double-blind, active control trial. Pain Physician. 2012;15(1):51-63.

10. Manchikanti L, Hirsch JA. Medicare physician payment rules for 2011: a primer for the neurointerventionalist. AJNR Am J Neuroradiol. 2011;32(6):E101-E104.

11. Manchikanti L, Hirsch JA. Medicare physician payment rules for 2011: a primer for the neurointerventionalist. J Neurointerv Surg. 2011;3(4): 399-402.

12. Kovacs FM, Urrutia G, Alarcon JD. Surgery versus conservative treatment for symptomatic lumbar spinal stenosis: a systematic review of randomized controlled trials. Spine. 2011;36(20):E1335-E1351.

13. Manchikanti L, Cash KA, Pampati V, Wargo BW, Malla Y. Cervical epidural injections in chronic discogenic neck pain without disc herniation or radiculitis: preliminary results of a randomized, double-blind, controlled trial. Pain Physician. 2010;13(4):E265-E278.

14. Manchikanti L, Pampati V, Singh V, Boswell MV, Smith HS, Hirsch JA. Explosive growth of facet joint interventions in the Medicare population in the United States: a comparative evaluation of 1997, 2002, and 2006 data. BMC Health Serv Res. 2010;10:84.

15. Manchikanti L, Cash KA, McManus CD, Pampati V. Fluoroscopic caudal epidural injections with or without steroids in managing pain of lumbar spinal stenosis: one year results of randomized, double-blind, active-controlled trial. J Spinal Disord. 2012;25(4):226-234.
16. Manchikanti L, Cash KA, McManus CD, Damron KS, Pampati V, Falco FJ. A randomized, double-blind controlled trial of lumbar interlaminar epidural injections in central spinal stenosis: 2-year follow-up. Pain Physician. 2015;18(1):79-92.

17. Moher D, Liberati A, Tetzlaff J, Altman DG. Preferred reporting items for systematic reviews and meta-analyses: the PRISMA statement. PLoS Med. 2009;6(7):e1000097.

18. Jadad AR, Moore RA, Carroll D, et al. Assessing the quality of reports of randomized clinical trials: is blinding necessary? Control Clin Trials. 1996;17(1):1-12.

19. Kjaergard LL, Villumsen J, Gluud C. Reported methodologic quality and discrepancies between large and small randomized trials in metaanalyses. Ann Intern Med. 2001;135(11):982-989.

20. Higgins JP, Thompson SG, Deeks JJ, Altman DG. Measuring inconsistency in meta-analyses. BMJ. 2003;327(7414):557-560.

21. Mantel N, Haenszel W. Statistical aspects of the analysis of data from retrospective studies of disease. J Nat Cancer Inst. 1959;22(4): 719-748.

22. DerSimonian R, Laird N. Meta-analysis in clinical trials. Control Clin Trials. 1986;7(3):177-188

23. Egger M, Davey Smith G, Schneider M, Minder C. Bias in meta-analysis detected by a simple, graphical test. BMJ. 1997;315(7109):629-634.

24. Manchikanti L, Pampati V, Cash KA. Protocol for evaluation of the comparative effectiveness of percutaneous adhesiolysis and caudal epidural steroid injections in low back and/or lower extremity pain without post surgery syndrome or spinal stenosis. Pain Physician. 2010; 13(2):E91-E110.

25. Kepler C. Epidural injections with glucocorticoid and lidocaine for spinal stenosis did not confer additional benefit compared with lidocaine alone. J Bone Joint Surg Am. 2015;97(4):342.

26. Friedly JL, Comstock BA, Turner JA, et al. A randomized trial of epidural glucocorticoid injections for spinal stenosis. New Engl J Med. 2014;371(1):11-21.

27. Manchikanti L, Cash KA, McManus CD, Pampati V, Abdi S. Preliminary results of a randomized, equivalence trial of fluoroscopic caudal epidural injections in managing chronic low back pain: Part 4 - Spinal stenosis. Pain Physician. 2008;11(6):833-848.

28. Manchikanti L, Cash KA, McManus CD, Pampati V, Singh V, Benyamin R. The preliminary results of a comparative effectiveness evaluation of adhesiolysis and caudal epidural injections in managing chronic low back pain secondary to spinal stenosis: a randomized, equivalence controlled trial. Pain Physician. 2009;12(6): E341-E354.

29. Manchikanti L, Cash KA, McManus CD, Pampati V, Fellows B. Results of 2-year follow-up of a randomized, double-blind, controlled trial of fluoroscopic caudal epidural injections in central spinal stenosis. Pain Physician. 2012;15(5):371-384.

30. Manchikanti L, Malla Y, Cash KA, McManus CD, Pampati V. Fluoroscopic epidural injections in cervical spinal stenosis: preliminary results of a randomized, double-blind, active control trial. Pain Physician. 2012; 15(1):E59-E70.

31. Tafazal S, Ng L, Chaudhary N, Sell P. Corticosteroids in periradicular infiltration for radicular pain: a randomised double blind controlled trial. One year results and subgroup analysis. Eur Spine J. 2009;18(8):1220-1225.

32. Radcliff K, Kepler C, Hilibrand A, et al. Epidural steroid injections are associated with less improvement in patients with lumbar spinal stenosis: a subgroup analysis of the Spine Patient Outcomes Research Trial. Spine. 2013;38(4):279-291.

33. Cuckler J. The use of epidural steroids in the treatment of lumbar radicular pain. J Bone Joint Surg Am. 1986;68(5):788-789.

34. Ng L, Chaudhary N, Sell P. The efficacy of corticosteroids in periradicular infiltration for chronic radicular pain: a randomized, double-blind, controlled trial. Spine. 2005;30(8):857-862.

35. Koc Z, Ozcakir S, Sivrioglu K, Gurbet A, Kucukoglu S. Effectiveness of physical therapy and epidural steroid injections in lumbar spinal stenosis. Spine. 2009;34(10):985-989. 
36. Fukusaki M, Kobayashi I, Hara T, Sumikawa K. Symptoms of spinal stenosis do not improve after epidural steroid injection. Clin J Pain. 1998;14(2):148-151.

37. Verbiest $H$. A radicular syndrome from developmental narrowing of the lumbar vertebral canal. J Bone Joint Surg Br. 1954;36-b(2):230-237.

38. Manchikanti L. Role of neuraxial steroids in interventional pain management. Pain Physician. 2002;5(2):182-199.

39. Byrod G, Otani K, Brisby H, Rydevik B, Olmarker K. Methylprednisolone reduces the early vascular permeability increase in spinal nerve roots induced by epidural nucleus pulposus application. J Orthop Res. 2000;18(6):983-987.

40. Lundin A, Magnuson A, Axelsson K, Nilsson O, Samuelsson L. Corticosteroids peroperatively diminishes damage to the C-fibers in microscopic lumbar disc surgery. Spine. 2005;30(21):2362-2367; discussion 2368.

41. Hayashi N, Weinstein JN, Meller ST, Lee HM, Spratt KF, Gebhart GF. The effect of epidural injection of betamethasone or bupivacaine in a rat model of lumbar radiculopathy. Spine. 1998;23(8):877-885.

42. Manchikanti L, Singh V, Falco FJ, Cash KM, Fellows B. Cervical medial branch blocks for chronic cervical facet joint pain: a randomized, double-blind, controlled trial with one-year follow-up. Spine. 2008;33(17):1813-1820.

43. Manchikanti L, Singh V, Falco FJ, Cash KA, Pampati V. Lumbar facet joint nerve blocks in managing chronic facet joint pain: one-year follow-up of a randomized, double-blind controlled trial: Clinical Trial NCT00355914. Pain Physician. 2008;11(2):121-132.
44. Manchikanti L, Singh V, Falco FJ, Cash KA, Pampati V. Effectiveness of thoracic medial branch blocks in managing chronic pain: a preliminary report of a randomized, double-blind controlled trial. Pain Physician. 2008;11(4):491-504.

45. Manchikanti L, Cash KA, McManus CD, Pampati V, Smith HS. Preliminary results of a randomized, equivalence trial of fluoroscopic caudal epidural injections in managing chronic low back pain: Part $1-$ Discogenic pain without disc herniation or radiculitis. Pain Physician. 2008;11(6):785-800.

46. Liu K, Liu P, Liu R, Wu X, Cai M. Steroid for epidural injection in spinal stenosis: a systematic review and meta-analysis. Drug Des Devel Ther. 2015;9:707-716.

47. Manchikanti L, Boswell MV, Singh V, et al. Comprehensive evidencebased guidelines for interventional techniques in the management of chronic spinal pain. Pain Physician. 2009;12(4):699-802.

48. Manchikanti L, Boswell MV, Datta S, et al. Comprehensive review of therapeutic interventions in managing chronic spinal pain. Pain Physician. 2009;12(4):E123-E198.

49. Conn A, Buenaventura RM, Datta S, Abdi S, Diwan S. Systematic review of caudal epidural injections in the management of chronic low back pain. Pain Physician. 2009;12(1):109-135.
Drug Design, Development and Therapy

\section{Publish your work in this journal}

Drug Design, Development and Therapy is an international, peerreviewed open-access journal that spans the spectrum of drug design and development through to clinical applications. Clinical outcomes, patient safety, and programs for the development and effective, safe, and sustained use of medicines are a feature of the journal, which

\section{Dovepress}

has also been accepted for indexing on PubMed Central. The manuscript management system is completely online and includes a very quick and fair peer-review system, which is all easy to use. Visit http://www.dovepress.com/testimonials.php to read real quotes from published authors.

Submit your manuscript here: http://www.dovepress.com/drug-design-development-and-therapy-journal 